\section{Biometrical Studies on the Ovaries of Slaughtered Egyptian Balady Does During different phases of Estrous Cycle and Seasons}

A.M. Osman ${ }^{1}$; H. A. Hussein ${ }^{1}$ and Mervat S. Hassan ${ }^{2 *}$

${ }^{1}$ Department of Theriogenology, Faculty of Veterinary
Medicine, Assiut University, Assiut, Egypt.
${ }^{2}$ Department of Theriogenology, Faculty of Veterinary
Medicine, New Valley University.

* Corresponding Author

Mervat S. Hassan, Department of

Theriogenology, Faculty of Veterinary

Medicine, New Valley University. Mervat@vet.nvu.edu.eg

Submitted 5/13/2021

Accepted 6/13/2021



To study the biometrical data of the ovaries from slaughtered Balady does in relation to estrous cycle and seasons, a total number of 127 normal pair ovaries were taken for this purpose in Assiut province. The obtained materials were classified according to phases of estrus cycle (Proestrous 39, Estrus 12, Metestrus 23 and Diestrus 53) and as well according to seasons (Autumn 36, Winter 40, Spring 26 and Summer 25). The biometry of the ovaries included the length, breadth, thickness and weight. The surface follicles and corpora lutea were counted in each ovary and their diameters measured. The follicles were classified according to their size into: small $(<3 \mathrm{~mm})$, medium $(3-5 \mathrm{~mm})$ and large $(>5 \mathrm{~mm})$. The ovaries of does were small, almond shape and shiny. The right ovaries are significantly larger than the left $(\mathrm{P}<0.01)$. Among phases of estrous cycle, the heaviest ovarian weights (left and right) were recorded during diestrus, followed by metestrus, estrus then proestrus. The ovarian length, breadth and thickness showed the same pattern of variations with significant differences $(P<0.01)$. The largest average values recorded for ovarian length, breadth, thickness and weight were found in autumn followed by winter, spring and summer. Differences were significant in most of these criteria $(\mathrm{P}<0.01)$. The highest values recorded for the right ovarian weight noticed during autumn, in the diestrus phase of the cycle, $(1.56 \pm 0.22 \mathrm{~g})$ while the lowest value was present in left ovary during summer in proestrus $(0.79 \pm 0.52 \mathrm{~g})$. The right ovaries carried the heaviest C.L. and the larger numbers of follicles among all samples. The total number of all follicles (small, medium and large) is significantly higher $(\mathrm{P}<0.01)$ in right than left ovaries $(110.97 \pm 11.18$ versus $106.38 \pm 13.09)$. The autumn has the largest values for the total numbers of follicles followed by winter, spring and summer. The maximum number of C. L. per doe reached 6 , in single case, while in rare occasion a single ovary carried $4 \mathrm{C}$. L. In the majority of cases the ovary carried 1-2 C. L. The ratios between single C.L. weight and intact ovarian weight were 26.9, 24.6, 23.8 and 23.4 percentages during autumn, winter, spring and summer respectively.

Keywords: Balady, Does, Estrous, Ovary, Breeding season.

\section{Introduction}

Ovaries of doe are almond-shaped, paired, and located on each side of the pelvic cavity. Each weighed 0.5 to 3 grams dependent on the stage of the reproductive cycle. They produce the ova or female gametes and sex steroid hormones such as estrogen and progesterone (Morrow, 1986). The ovaries are smooth and shiny (Smith, 1986). Moreover, the right ovary is generally more active than the left. Polynuclear and poly-ovular follicles are common in the goat's ovary, but in primordial stages. Hafez and Hafex (2000) cited that the ovaries in does are of variable shape, depending upon the structures which are present. The longest dimension being about $2.2 \mathrm{~cm}$. The largest follicles reach a maximum size of about $1.2 \mathrm{~cm}$ in diameter, and when they protrude from the surface often have a bluish tinge. Rahman et al (1977) reported that right ovary is heavier $(0.90 \mathrm{~g})$ than the left one $(0.85 \mathrm{~g})$. In addition, Al-Baggal et al (1993) found that the mean length, width and thickness of right ovaries obtained from non-pregnant specimens of Iraqi goats were 1.99 $\pm 0.42,1.4 \pm 0.42$ and $0.89 \pm 0.24 \mathrm{~cm}$ respectively, while the mean weight was $1.64 \pm 0.86 \mathrm{~g}$. Biometric 
values of the left ovary were $1.97 \pm 0.39,1.38 \pm 0.30$, $0.87 \pm \mathrm{cm}$ and $1.62 \pm 0.82$, respectively. Islam et al (2007) reported that ovaries with C.L. are larger in dimensions and weight than ovaries without C.L. Moreover, the same authors found that right ovaries are larger and heavier than the left in Bangladesh goat. Gupta et al (2011), concluded from his studies on Biometry of Female Genital Organs of Black Bengal Goat that the lengths of the right and left ovaries were $1.453 \pm 0.034$ and $1.410 \pm 0.026 \mathrm{~cm}$, respectively. Mean weight of left ovary was $0.5944 \pm 0.06 \mathrm{gm}$ and that of right ovary was $0.614 \pm 0.07 \mathrm{~g}$. In Egypt, only $\mathrm{El}$ Agawany (1987) studied the development of its genital tract during the postnatal period of life and recorded that the rate of growth in the ovary during the first 5 months of age was marked. After this age, the growth rate became very gradual. At 7th month of age the weight of single ovary averaged $0.95 \pm 0.02 \mathrm{~g}$.Islam et al (2007) recorded in Bangladesh goat that the total numbers of follicles per right and left ovary to be $4.45 \pm 0.19$ and $4.16 \pm 0.37$ respectively. The average number of vesicular follicles in Black Bengal nanny goat ranged from 10.4-21.20 vs., 11.80-17.60 and 3.40-4.40 for small, medium and large follicles (Rao et al, 1982). Al-Baggal et al (1993) reported that the mean diameter and weight of corpora lutea in the right ovary were $1.25 \pm 0.31 \mathrm{~cm}$ and $0.79 \pm 0.33 \mathrm{~g}$, respectively, and $1.05 \pm 0.30 \mathrm{~cm}$ and $0.70 \pm 0.20 \mathrm{~g}$ for the left ovary of Iraqi goat. The first appearance of $\mathrm{C}$. L. in the ovary of Balady goat was at 7th month of age (El Agawany (1987). Moreover, the ovaries of goat usually carry mature CL about 5 days from the onset of heat (Amrawi et al (1993) Bari et al (2011) revealed in Black Bengal goats that the mean number of antral follicles per ovary was $34 \pm 10(\mathrm{n}=7)$ in winter which was significantly higher $(\mathrm{P}<0.05)$ than those in summer $(19 \pm 2 ; n=7)$. The number of secondary follicles per ovary was also higher $(\mathrm{P}<0.05)$ in winter $(52 \pm 5)$ than summer $(35 \pm 10)$ season. During summer season, the ovaries contained $19 \pm 4 \%$ primary and $71 \pm 4 \%$ primordial follicles whereas these values were $52 \pm 3 \%$ and $20 \pm 1 \%$, respectively during winter season. The results indicate that lower rate of development and higher rate of degeneration were occurred in goat ovaries during summer than winter season.Out of the available literature biometrical information on the ovaries of slaughtered Balady does appeared lacking. Moreover, the changes occurring in the ovaries of slaughtered non pregnant adult does during estrous cycle and as well during seasons appeared necessary for such animal.

\section{Materials and Methods}

A total number of 127 intact genital organs were selected freshly from slaughtered, healthy; adult does more than one year of age. These animals were of unknown breeding history and slaughtered in four local abattoirs near Assiut City. Their meat was suitable for consumption.

The genital tract excised from each animal and transported in a plastic bag to the lab. The present materials were collected during all seasons of the year (from April 2012 to September 2014).

The obtained materials were classified according to the different phases of estrus cycle (Proestrous 39, Estrus 12, Metestrus 23 and Diestrus 53) and as well according to seasons (Autumn 36, Winter 40, Spring 26 and Summer 25). The size, consistency and color of the corpora lutea and the size of follicles guide us to the abovementioned classification of the estrous cycle as mentioned in slaughtered buffalo cows (Osman, 2012) putting into consideration the shorter length of the cycle in doe (17 days; El Agawany 1978).

In the lap, each genital tract was dissected free from the surrounding broad ligament and other tissues. At first, the morphological appearance of the organ was performed before taking any measurement. The different organs were separated free and weighed to the nearest $0.01 \mathrm{gm}$ using electronic balance (ACCULAB-V-1mg).

The biometrical investigation included the measurements of the different dimensions of each ovary using Vernier Caliber to the nearest $0.1 \mathrm{~cm}$. The length (from pole to pole), breadth (from side to side) and thickness (from attached portion to the free surface) were measured. The weight of intact ovary was taken.

The surface follicles and corpora lutea were counted in each ovary using magnifying glass and their diameters measured. The follicles were classified according to their size into: small $(2-3 \mathrm{~mm})$, medium $(3-5 \mathrm{~mm})$ and large $(>5 \mathrm{~mm})$.

The corpora lutea in many occasions weighed separately to the nearest $0.01 \mathrm{~g}$ to search for any relation to the ovarian weight at various reproductive conditions among does. Moreover, the shape, color, consistency and reliability to enucleation of each $\mathrm{CL}$ were evaluated to assess the classification of the estrous cycle for each organ. 
Data obtained expressed as Mean \pm MSD and subjected for statistical analysis using the student t-test and correlation between two factors according to Snedecor and Cochran (1980) and The Costat Computer Program (1986).

\section{Results}

The ovaries of slaughtered does were small, almond shape and shiny. The ovarian shape varies according to the presence of follicles (F) or corpora lutea (C.L.). In situ, the ovaries situated at the end of the convoluted uterine horns near the region of uterine body laterally (Fig.1\&2).

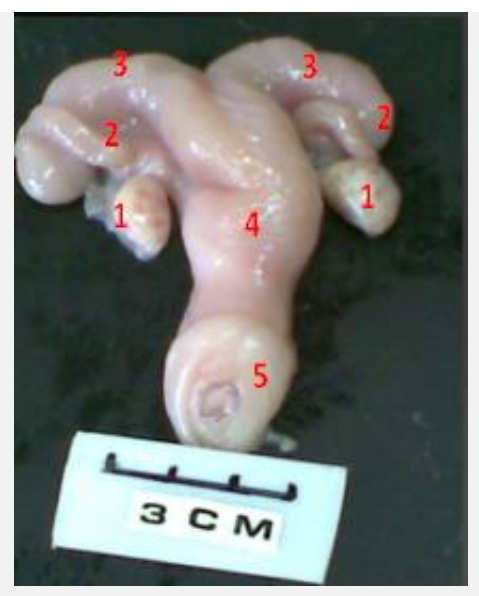

Figure (1): Genitalia of slaughtered doe showing the ovaries with multiple follicles, convoluted uterine horns and external os cervix. 1-ovary; 2,3-uterine horn; 4-uterine body; 5-os cervix.

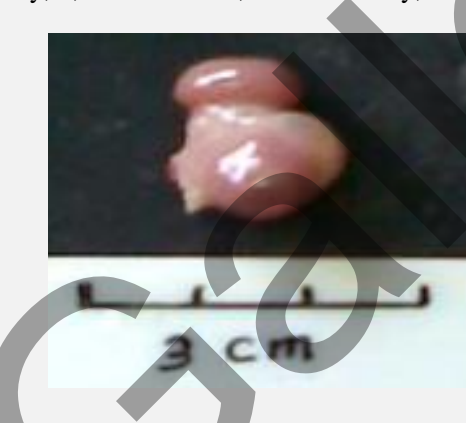

Figure (2): showing ovary with two C. L. and large size follicle

Tables 1 and 2, showed the changes occurring in the biometry of the ovaries among various reproductive conditions and during different seasons respectively. Generally, it is evident from these results that the right ovaries are Larger than the left.
Table 1. Biometry of the ovaries in slaughtered does as related to various reproductive conditions

\begin{tabular}{|c|c|c|c|c|}
\hline Criteria & $\begin{array}{c}\text { Proestrus } \\
\mathrm{N}=39\end{array}$ & $\begin{array}{l}\text { Estrus } \\
\mathrm{N}=12\end{array}$ & $\begin{array}{c}\text { metestrus } \\
\mathrm{N}=23\end{array}$ & $\begin{array}{c}\text { Diestrus } \\
\mathrm{N}=53\end{array}$ \\
\hline $\begin{array}{c}\frac{\text { Length }(\mathrm{cm})}{\text { Left }} \\
\text { Right }\end{array}$ & $\begin{array}{l}1.32 \pm 0.11 \\
1.35 \pm 0.18\end{array}$ & $\begin{array}{l}1.35 \pm 0.15 \\
1.40 \pm 0.17\end{array}$ & $\begin{array}{l}1.38 \pm 0.10 \\
1.42 \pm 0.18\end{array}$ & $\begin{array}{l}1.46 \pm 0.15 \\
1.50 \pm 0.14\end{array}$ \\
\hline $\begin{array}{l}\frac{\text { Breadth }}{(\mathrm{cm})} \\
\text { Left } \\
\text { Right }\end{array}$ & $\begin{array}{c}0.66 \pm 0.05^{* *} \\
0.74 \pm 0.01^{* * *} \\
\end{array}$ & $\begin{array}{c}0.68 \pm 0.06^{* *} \\
0.74 \pm 0.07^{*}\end{array}$ & $\begin{array}{l}0.82 \pm 0.05 \\
0.87 \pm 0.08\end{array}$ & $\begin{array}{c}0.87 \pm 0.02 * * \\
0.93 \pm 0.04^{* * *}\end{array}$ \\
\hline 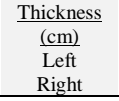 & $\begin{array}{l}0.94 \pm 0.13 \\
0.97 \pm 0.19\end{array}$ & $\begin{array}{l}0.97 \pm 0.14 \\
1.02 \pm 0.20\end{array}$ & $\begin{array}{l}1.05 \pm 0.18 \\
1.13 \pm 0.18 \\
\end{array}$ & $\begin{array}{l}1.08 \pm 0.16 \\
1.16 \pm 0.19\end{array}$ \\
\hline $\begin{array}{c}\text { Weight (g) } \\
\text { Left } \\
\text { Right }\end{array}$ & $\begin{array}{c}0.99 \pm 0.03 * * \\
1.03 \pm 0.02 * * *\end{array}$ & $\begin{array}{l}1.06 \pm 0.07 * \\
1.21 \pm 0.09^{*}\end{array}$ & $\begin{array}{r}1.23 \pm 0,04 * * * * \\
1.38 \pm 0.06\end{array}$ & $\begin{array}{c}1.36 \pm 0.09^{* *} \\
1.48 \pm 0.07^{* * *}\end{array}$ \\
\hline
\end{tabular}

Table 2. Biometry of the ovaries in slaughtered does as related to



Among different phases of estrous cycle, table 1 showed that the heaviest ovarian weights (left and right) were recorded during diestrus, followed by metestrus, estrus then proestrus. Moreover, the other dimensions of the ovaries (length, breadth and thickness) showed the same pattern of variations within the different phases of the cycle. Significant differences were noticed between these criteria at a level of $\mathrm{P}<0.05-0.001$.

It is noticed during the performance of these biometrical studies that during diestrus, the right ovaries carried the heaviest C.L. among all samples. However, the maximum values recorded for ovarian length, breadth, thickness and weight in all collected genitalia were $2.05,1.25,1.58 \mathrm{~cm}$ and $1.9 \mathrm{gm}$ respectively.

In other hand, it was noticed from table 2 that the highest average values for length, breadth, thickness and weight were found in autumn followed by spring, winter and summer. Differences between seasons were significant especially in ovarian weight at a significant of $\mathrm{P}<0.05-0.001$. However, differences between 
seasons were negligible especially with regard to thickness and breadth of the ovaries.

However, the highest values recorded for the right ovarian weight were noticed during autumn and in the diestrus phase of the cycle $(1.51 \pm 0.07 \mathrm{~g})$ while the lowest value was present in left ovary during summer and in the proestrus phase $(0.99 \pm 0.03 \mathrm{~g})$.

As far as the numbers of follicles per ovaries as related to various reproductive conditions and to different seasons, were concerned, the results were shown in tables 3 and 4 .

Table 3. Numbers of follicles (small, medium and large) in slaughtered does as related to various reproductive conditions

\begin{tabular}{|c|c|c|c|c|c|}
\hline $\begin{array}{c}\text { Follicles } \\
\text { Diameter } \\
(\mathrm{mm})\end{array}$ & & $\begin{array}{c}\text { Proestrus } \\
(\mathrm{n}=39)\end{array}$ & $\begin{array}{c}\text { Estrus } \\
(\mathrm{n}=12)\end{array}$ & $\begin{array}{c}\text { Metestrus } \\
(\mathrm{n}=23)\end{array}$ & $\begin{array}{c}\text { Diestrus } \\
(\mathrm{n}=53)\end{array}$ \\
\hline \multirow{2}{*}{$\begin{array}{c}\text { Small } \\
(<3 \mathrm{~mm})\end{array}$} & Left & $12.54 \pm 1.67$ & $13.68 \pm 1.70$ & $11.97 \pm 1.43$ & $13.15 \pm 1.61$ \\
\cline { 2 - 6 } & Right & $12.82 \pm 1.85$ & $13.87 \pm 1.65$ & $12.31 \pm 1.73$ & $13.27 \pm 1.37$ \\
\hline \multirow{2}{*}{$\begin{array}{c}\text { Medium } \\
(3-5 \mathrm{~mm})\end{array}$} & Left & $5.95 \pm 0.90$ & $5.85 \pm 0.89$ & $6.66 \pm 0.81$ & $6.30 \pm 0.88$ \\
\cline { 2 - 6 } & Right & $6.15 \pm 0.99$ & $6.10 \pm 0.81$ & $6.83 \pm 0.98$ & $6.61 \pm 0.24$ \\
\hline $\begin{array}{c}\text { Large } \\
(>5 \mathrm{~mm})\end{array}$ & Left & $4.47 \pm 0.71$ & $4.77 \pm 0.88$ & $4.16 \pm 0.75$ & $3.69 \pm 0.86$ \\
\cline { 2 - 6 } & Right & $4.58 \pm 0.61$ & $4.80 \pm 0.83$ & $4.33 \pm 0.81$ & $4.06 \pm 0.81$ \\
\hline \multirow{2}{*}{ Total } & Left & $22.96 \pm 3.26$ & $24.30 \pm 2.44$ & $22.79 \pm 3.18$ & $23.14 \pm 2.61$ \\
\cline { 2 - 6 } & Right & $23.55 \pm 3.22$ & $24.77 \pm 2.57$ & $23.47 \pm 3.16$ & $23.94 \pm 2.70$ \\
\hline
\end{tabular}

Table 4. Numbers of follicles (small, medium and large) in does as related to seasons

\begin{tabular}{|c|c|c|c|c|c|}
\hline \multicolumn{2}{|c|}{$\begin{array}{c}\text { Follicles } \\
(\mathrm{mm})\end{array}$} & $\begin{array}{c}\text { Autumn } \\
(\mathrm{n}=36)\end{array}$ & $\begin{array}{c}\text { Winter } \\
(\mathrm{n}=40)\end{array}$ & $\begin{array}{c}\text { Spring } \\
(\mathrm{n}=26)\end{array}$ & $\begin{array}{c}\text { Summer } \\
(\mathrm{n}=25)\end{array}$ \\
\hline \multirow{2}{*}{$\begin{array}{c}\text { Small } \\
(<3 \mathrm{~mm})\end{array}$} & Left & $13.31 \pm 1.65$ & $12.78 \pm 1.62$ & $12.90 \pm 1.67$ & $12.35 \pm 1.64$ \\
\cline { 2 - 6 } & Right & $13.45 \pm 1.43$ & $12.98 \pm 1.38$ & $13.18 \pm 1.42$ & $12.66 \pm 1.23$ \\
\hline \multirow{2}{*}{$\begin{array}{c}\text { Medium } \\
(3-5 \mathrm{~mm})\end{array}$} & Left & $6.75 \pm 0.85$ & $6.35 \pm 0.63$ & $5.91 \pm 0.87$ & $5.75 \pm 0.73$ \\
\cline { 2 - 6 } & Right & $6.98 \pm 0.85$ & $6.37 \pm 0.77$ & $6.23 \pm 0.69$ & $6.11 \pm 0.81$ \\
\hline \multirow{2}{*}{$\begin{array}{c}\text { Large } \\
(>5 \mathrm{~mm})\end{array}$} & Left & $4.81 \pm 0.83$ & $4.00 \pm 0.79$ & $4.30 \pm 0.76$ & $3.98 \pm 0.89$ \\
\cline { 2 - 7 } & Right & $4.93 \pm 0.86$ & $4.20 \pm 0.83$ & $4.53 \pm 0.81$ & $4.11 \pm 0.73$ \\
\hline \multirow{2}{*}{ Total } & Left & $24.87 \pm 2.80$ & $23.13 \pm 2.97$ & $23.11 \pm 3.69$ & $22.08 \pm 3.74$ \\
\cline { 2 - 7 } & Right & $25.36 \pm 2.97$ & $23.55 \pm 2.78$ & $23.94 \pm 3.62$ & $22.88 \pm 3.56$ \\
\hline
\end{tabular}

Out of table 3, the numbers of follicles as related to various reproductive conditions showed that the highest vales for small size follicles $(<3 \mathrm{~mm})$, for left and right ovaries, were present in estrus and diestrus phases while the lowest values were present during proestrus and metestrus. The numbers of medium size follicles were dominated during metestrus and diestrus then decreased in other phases of the cycle. However, the numbers of large follicles and as well the total number of follicles were higher in estrus than any other phases of the cycle without any significant difference.

On the other side, numbers of follicles as related to seasons were presented in table 4 and showed that the right ovaries always have the larger numbers of follicles. The total number of all follicles (small, medium and large) is higher in right than left ovaries $(95.73 \pm 6.46$ versus $92.19 \pm 6.43$ respectively).

It is noticed that the autumn has the largest values recorded for small and large size follicles followed by spring, winter and summer. With regard to the medium size follicle, the largest values were present in autumn followed by winter, spring and summer. There are no significant differences between the numbers of different size follicles among seasons.

Significant correlation $(\mathrm{r}=0.78,<\mathrm{P} 0.01)$ was present between ovarian weight and total number of the follicles.

The descriptive morphology of the C. L. was studied during the diestrus phase. They were found to be protruded from the surface of the ovary, of brownish coloration and easily enucleated. It was fewer firms in consistency than the ovary and sometime destructed with pressure especially during its newly formed stage.

With regard to the weight and diameter of C. L. per ovary during diestrus in all seasons, table 5 showed that the right side still has the larger values than the left one. Significant difference $(\mathrm{P}<0.05-\mathrm{p}<0.001))$ was noticed in $\mathrm{C}$. L. weight and diameter between different seasons, mainly between autumn and summer. It is of importance to mention that when more than C. L. lodged the ovary, the heaviest one was taken into consideration. Therefore, the values presented in this table represent single C. L. Moreover, in rare occasion one ovary can carry up to $6 \mathrm{C}$. L. among all samples but in the majority of cases the ovary carried 1-3 C. L. However, the maximum values recorded for weight and diameter of C. L. in all samples were 0.49 $\mathrm{g}$ and $1.25 \mathrm{~cm}$ respectively.

Table 5. Diameter and weight of corpora lutea per ovary in slaughtered does during diestrus in all seasons (MSD)

\begin{tabular}{|c|c|c|c|c|c|}
\hline \multicolumn{2}{|c|}{ C.L. } & Autumn & Winter & Spring & Summer \\
\hline \multirow{2}{*}{ 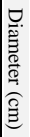 } & Left & $0.96 \pm 0.08 * * *$ & $0.71 \pm 0.08 *$ & $\begin{array}{c}0.88 \pm 0.08 * * \\
*\end{array}$ & $\begin{array}{c}0.41 \pm 0.05^{* *} \\
*\end{array}$ \\
\hline & Right & $0.99 \pm 0.09 * * *$ & $\begin{array}{c}0.73 \pm 0.06^{*} \\
*\end{array}$ & $0.90 \pm 0.06$ & $\begin{array}{c}0.43 \pm 0.02 * * \\
*\end{array}$ \\
\hline \multirow{2}{*}{  } & Left & $0.30 \pm 0.06$ & $0.26 \pm 0.06$ & $0.29 \pm 0.05$ & $0.23 \pm 0.03$ \\
\hline & Right & $0.33 \pm 0.03 *$ & $0.28 \pm 0.09$ & $0.30 \pm 0.08$ & $0.25 \pm 0.01 *$ \\
\hline
\end{tabular}


The ratio between C. L. weight (single) and ovarian weight (one side) was $22 \%$ during diestrum in autumn. Expected higher percentages occurred when more than C.L. present in the ovary.

Significant correlation $(\mathrm{r}=0.73,<\mathrm{P} 0.01)$ was present between C. L. total weight and C. L. number.

\section{Discussion}

The biometrical investigations (length, breadth, thickness and weight) carried out on the ovaries of slaughtered adult non pregnant does of the present work appeared within the scope of the published researches on other foreign breeds by Rahman et al (1977) and Al Baggal et al (1993) in Iraqi goats, Islam et al (2007) in Pakistan goats and Gupta, (2011) in Black Bengal goat). However, Hafez and Hafex (2000) reported higher maximum values of $2.2 \mathrm{~cm}$ for the longest length of the ovary dimension in goat.It seems possible that the wide variations in live weight between goat breeds did not accompanied by similar variations in ovarian dimensions and weight. Thus, both criteria might be of independent genetic origin. As far as the changes occurring in the ovarian biometry among different phases of estrous cycle are concerned, the right ovaries are much active than the left with a significant difference especially in ovarian weights and as well between diestrus and other phases of the cycle especially with regard to ovarian breadth and weight. Most of the researches approved the higher activity of the right ovary than the left one in goat. It is of interest to mention that El Agawany (1987) cited that after 3 month of age the right ovary was significantly larger than the left in Balady goats. Before this age negligible difference could be observed. The average ovarian weight in the present work $(1.16 \mathrm{~g})$ is somewhat higher than $0.99 \mathrm{~g}$ as reported by El Agawany (1987). The last author studied the changes occurring in the reproductive tract of Balady goat during the postnatal period of life up to 210 days. The obtained data from our work were collected from adult goats more than one year of age. Thus, such difference in age might be responsible for the observed difference in the average ovarian weight between both studies. In Awassi sheep, Koujan (1974) remarked that ovarian weight averaged $1.17 \pm 0.05 \mathrm{~g}$ for the left ovary and $1.14 \pm 0.05 \mathrm{~g}$ for the right one without any valuable difference between them. During diestrus, the significant increase in ovarian breadth and weight than other seasons could be attributed to the presence C. L. in the ovaries of slaughtered non pregnant does under investigation. The effect of seasons on the results of ovarian biometry showed great tendency to be larger in the autumn. Ovarian weight was the only criteria that have significant higher value in autumn than other seasons. This finding pointed to the presence of a great tendency for the ovaries in does to be more active in autumn. Similar studies on slaughtered goats appeared lacking in the literature at our disposal. However, it is well known that small ruminants including goat have seasonal variation in reproduction. El Barbary and Abdel Latif (1984), Kandil (1988), Mostafa (1992) and El Amrawi et al (1994) declared that in Egypt, does like ewes are seasonal polyestrous and their cyclic activities start when the daylight shortens. Schoenian (2009) cited that small ruminant are shortday breeder (fall breeders). As photoperiod increases in the spring and early summer, the activity of the reproductive gland, hypothalamus and pituitary decreased due to the effect of light on the retina and brain. Melatonin secreted from the pineal gland has important effects on reproductive function through modulating the environmental lighting to the various parts of the body. El Wishy et al (1976) reported in Egyptian fat-tailed ewe that the highest incidence of normal cycling ovaries was during SeptemberNovember $(81.5 \%)$, while the lowest incidence during March-May (57.5\%). In Awassi Syrian sheep, Koujan (1974) recorded the highest values for ovarian weight during summer followed by spring. The different species and altitude might be responsible for such difference between Awassi sheep and Balady goat. With regard to the number of small, medium and large ovarian follicles, the obtained results showed no significant differences between phases of estrous cycle and among seasons. During estrus, the numbers of small, large and total follicles were the highest among all slaughtered does but not at a significant level. Moreover, similar trend was noticed among different seasons and the autumn has the largest vales. Rao et al (1982) recorded that the average number of small follicles ranged from 10.4-21.2 versus 11.8-17.6 and 3.4-4.4 for medium and large follicles in Black Bengal nanny goat. These results are nearly similar to the present data with slaughtered Balady does. Sadykov et al (1973) mentioned that the average of large follicles $>4 \mathrm{~mm}$ per ewe average 29 in Alai semicoarse-wooled ewes which is nearly similar to the obtained results in Balady goat. These findings lead to the conclusion that 
typical breeding seasons in goat reproduction could not be approved. History from goat owners and breeders pointed to the fact that kidding occurs all over the year. The presence of different size follicles in the ovaries of Balady goat all over the year coincides with those published in sheep by Koujan (1974) and in buffalo by Osman and Shehata (2005). Meaning that in normal ovaries, the presence of different size follicles could be considered as a basic structure of the ovaries. Koujan (1974) reported for the diameter of large follicles in Awassi sheep $0.63 \mathrm{~cm}$ for the left ovary and $0.7 \mathrm{~cm}$ for the right. In fat-tailed sheep in Egypt, El Wishy (1984) recorded that the average number of follicles $>3 \mathrm{~mm}$ diameter per pair ovaries was higher in autumn (4.5-5) than other seasons (24.1). Such result indicates similarity of doe reproduction to ewe especially with regard to seasonal variation. The presence of significant correlation between ovarian weight and total follicle number indicates the role of gonad weight to the functional activity of the reproductive genitalia. Koujan (1974) in ewe reported $0.57 \pm 0.03$ and $0.95 \pm 0.07 \mathrm{~g}$ for ovarian weight in static and active ovaries during follicular phase respectively. The largest Graafian follicle reported in the studied Balady goat reached $1.25 \mathrm{~cm}$. Omar (1972) reported that Graafian follicle in Awassi doe ranged between 0.9 and $1.2 \mathrm{~cm}$. The diameters and weights of C. L. in slaughtered non pregnant adult Balady goat showed higher values in the right ovaries than the left at significant levels of $\mathrm{P}>0.05-0.001$. As a valuable information added to this result, El Agawany (1978) cited that no C. L. could be detected in growing slaughtered Balady goats up to 7 months of age where the first C. L. (0.75mm diameter) could be seen in the right ovary. It is concluded here that functional activity of the ovaries can be measured by the presence of C. L. rather than follicles which are permanently present in the ovaries even during the early postnatal life (before age of puberty). In the present study estrous cycle length varied between (1719day). It seems possible the shortest cycle can be attributed to premature regression of the C. L. as cited by Oldham and Lindsay (1980) Moreover, Daily et al (1982) added that C. L. had local effect on the diameter and number of follicles. The weight of single C. L. in relation to the weight of ovary in Baldy does average $20.1 \%$. This ratio will be increased when the ovary has more than single C. L. Few does in the present work has up to $6 \mathrm{C}$. L. per both ovaries and up to 4 C.L. were recorded in one ovary. Single C. L. weight represents $30 \%$ of the ovary in buffalo cows (Osman and Shehata, 2005). Khori (1965) and others reported that twin births is rather higher in doe than ewe. With regard to the C.L. weight in slaughtered does, the obtained results revealed its comparable values with other breeds of sheep since no data cold be available for goat. Zimbelman et al (1959), Shalash and El Gindi (1986), Ginther (1986) and Omar (1972) reported a range from 0.33 to $0.76 \mathrm{~g}$ for single $\mathrm{C}$. $\mathrm{L}$. weight in different breeds of slaughtered sheep among them Merino and Awassi. The results of the present work showed higher values for the diameter and weight of C. L. during autumn than other seasons. Koujan (1974) reported in Awassi sheep maximum and minimum values of $0.87 \mathrm{~g}$, November (Autumn) and $0.15 \mathrm{~g}$ July (Summer) for the C.L. weight. Moreover, Calderon (1978) found higher percentages of ewes with C. L. during September through December. Our results support the conclusion that more activity in the reproduction of Balady goat occurs during autumn in Egypt.

\section{Conflict of interest}

The authors declare that they have no competing interest.

\section{References}

Al-Baggal, H. A. R., Al-Dahash, S. Y. A. and Alwan, A. F. (1993): Macroscopic study of the female genital system in Iraqi goats. Vet. Med. Mosul Univ. Iraq. 9, 4, 341-346.

Bari, M. A., Kabir, M. E., Sarker,V., Khan, N. A., and Momiruzzaman, M. (2011): Morphometric analysis of ovarian follicles of Black Bengal goats during winter and summer season. Bangladesh J. Anim. Sci. 40, 12 .

Calderon, R. (1978): Variations in ovarian activity in Corrie-dale x Criollo ewes in Cuba. Rev. Cubana Repord. Anim. 4: 69-80., (A. B. A. 48, 2534).

Costat Computer Program (1986): Version 3.03, Copyright C.C. P Software.

Dailey, R.A., Fogwell, R.L. and Thayne, W.V. (1982): Distribution of visible follicles on the ovarian surface in ewes. J. Anim. Sci. 54, 1196-20.

El-Agawany, A.A.A. (1987): Pubertal development and estrous activity in Baladi Goats. Ph.D. Thesis, Theriogenology, Cairo University. 
El-Amrawi, G. A., Hussein, F. M. and Iman, E. ElBawab (1993): Fertility of the Saanen Goats following induction of Estrus using Prostaglandin F2 $\alpha$. Assiut Vet. Med. J. 29, 57.

El Amrawy, G. A., El Bawab, Eman E., Ezzo, Omima H. and Hussein, F. M. (1994): Peripheral serum progesterone and estradiol B17 hormone concentrations in Saanen goats during synchronization of estrus with vaginal sponge. 6th Sci.Cong., 20-22 Nov., Fac. Vet. Med., Assiut Univ.

El-Barbari, A.and Abd-El-Latif, M. (1984): Principles of animal production. Fac. Agric. Alex. Univ. Press.

El-Wishy, A. B., El-Sawaf, S. A. and Fouad, K. (1976): Some aspects of reproduction in fat-tailed sheep in subtropics. II. Seasonal variation in ovarian activity. Z. Teirzuch. Zuchtungsbiol., 93: 121-134.

El-Wishy, A. B. (1984): Seasonal variation in ovarian activity of Fat-Tailed sheep in the subtropics. Anim. Repord. Sci., 7: 563-567.

FAO and IAEA (2012): Animal production and Health Newsletter, ISSN 1011-2529, 55, Jan.

Ginther, O. J., (1986): Influence of exogenous progesterone and the uterus on ovarian activity in sheep. Endocrinology, 83: 613-61.

Gupta, M.D., Akter M.M., Gupta A.D., Das A. (2011): Biometry of Female Genital Organs of Black Bengal Goat. Int. J. Nat. Sci. 1, 1, 12-16.

Hafez, E. S. E., and Hafex, B. (2000): Reproduction in Farm Animals. 7th ed. New Jersey, Blackwell.

Islam, M.R., Khandoker, M.A.M.Y., Afroz, V., Rahman, M.G.M. and Khan, R.I. (2007):

Qualitative and quantitative analysis of goat ovaries, follicles and oocytes in view of in vitro production of embryos.J. Zhejiang Univ. Sci. B., 8 ,7, 465-469.

Kandil, O. (1988): Studies on the estrous cycle of goats with emphasis on hormone profile. M. V. Sc. Thesis, Fac. Vet. Med. Cairo Univ.

Khori, F. (1965): 7th Week science in Aleppo. 135147.

Koujan A. H. S. (1974): Morphogyn-ecological studies of the genitalia of Syrian Awassi ewes. M. V. Sc. Obst. Gynaec. and A. I. Cairo Univ.

Mostafa, M. (1992): Reproductive performance in goats with special reference to estrus synchronization. M. V. Sc. Thesis, Fac. Vet. Med. Alex. Univ.
Oldham, C. M. and Lindsay, D. R. (1980): Laparoscopy in the ewe - a photographic record of the ovarian activity of ewes experiencing normal or abnormal oestrous cycles. Anim. Reprod. Sci. 3, 119124. (A. B. A. 48, 6767).

Omar, M. A. (1972): Some reproductive patterns in sheep under desert conditions. M. D. Vet. Thesis, Cairo Univ., Giza, Egypt.

Osman, A. M. and Shehata, S. H. (2005): Effect of seasons on ovarian morphology and oocytes quality in slaughtered buffaloes. Assuit Vet. Med. J., 51, 105, 314-330.

Osman, A.M. (2013): Ovarian changes during estrous cycle in slaughtered buffaloes. ESARF. Ann Cong. Cairo Univ. Ain El Sokhn

Rahman, A., Hossain, A., Ahmed, M. V. and Sen, M. M. (1977): Studies on some reproductive performances and biometry of the female genital tract of Black Bengal goat. J. Anim. Sci., 47, 714-725.

Sadykov, R. E., Rabochev, V. K. and Sydykov, B. (1973): Reproductive characters of Alai semicoarse- wooled and Kirgiz Fine wool sheep. Ovtsevodstvo., 8, 31-32., (A. B. A. 42, 1107).

Schoenian, (2009): "Sheep 201": Nov., 8. <http// WWW. Sheep 101. Info/ 201/ ewerepro. Html>. Biol. Of Rep., 78, 552-562.

Shalash, M. R. and El- Gindi, M. (1986): Preliminary studies on some reproductive characters of Ausimi ewes. Veterinaria, Saraj., 17, 145-149.

Snedecor, B.W. and Cochran,W.G. (1980): Satistical methods. 7th Ed. Iowa state Univ. Press, Ames, Iowa, USA.

Zimbelman, A.L., Pope, A. L. and Casida, L. E. (1959): Effect of exogenous progesterone on the corpus. J. Anim. Sci., 18, 1327-1332.

\section{Cite this paper.}

A.M. Osman; H. A. Hussein and Mervat S. Hassan (2021). Biometrical Studies on the Ovaries of Slaughtered Egyptian Balady Does During different phases of Estrous Cycle and Seasons. New Valley Veterinary Journal. 1(1): 29-35. 